\title{
ACERCA DE LA «LIBERACIÓN» DE LOS SOBREVIVIENTES DE LA SHOÁ Y SUS MARCAS EN LA SUBJETIVIDAD
}

Rosa Zytner Tessler Dra. en Psicología de la UBA Profesora titular de la Facultad de Psicología de la UDELAR Miembro fundador de AUDEPP Correo electrónico: rzytner@psico.edu ORCID: 0000-0003-0499-5239 


\section{Resumen}

El artículo reflexiona en relación a lo elicitado por la llamada «liberación» de los sobrevivientes de la Shoá y sus marcas en la subjetividad, y problematiza su alcance desde distintas consideraciones. Ello incluye a los sobrevivientes y a sus descendientes, así como la propia implicación de pertenencia a la segunda generación, ubicada en la contemporaneidad cultural del siglo xx e inicios del siglo xxı. Dicha implicación produce resonancias afectivas, marcas que evidencian efectos de lo traumático en sus vertientes organizadoras y disruptivas de la organización psíquica, tanto en sus dimensiones psicoanalíticas como socioculturales, todo lo cual seguramente impregna este texto.

Pese al tiempo transcurrido y más allá de su propia especificidad, la Shoá continúa constituyendo un baluarte paradigmático y emblemático, con plena vigencia, de lo que han sido y siguen siendo episodios extremos de catástrofe social, que dan cuenta, radicalmente, de la violencia extrema ejercida por un ser humano sobre otro. Esto sigue impregnando actualmente, desde otras expresiones, el entramado psíquico y social.

Palabras clave: liberación, Auschwitz, repercusiones de la Shoá, subjetividad.

\section{On the Liberation of Shoah Survivors and their Subjectivity Scars Abstract}

This work attempts to reflect on what was elicited by the so-called "liberation" of the survivors of the Shoah and the scars left on their subjectivity, problematizing its scope from different points of view. This includes the survivors and their descendants, as well as the implication of belonging to the second generation, located in the cultural contemporaneity of the 20th century and the beginning of the 21 st century. This implication produces affective resonances, scars that show the effects of the traumatic in their organizing and disruptive aspects of the psychic organization, both in their psychoanalytic and sociocultural dimensions, that surely permeate this text.

Despite the time elapsed and beyond its own specificity, the Shoah continues to constitute a paradigmatic and emblematic bastion, with full force, of what have been and continue to be extreme episodes of social catastrophe that radically account for the extreme violence exercised by one human being over another, which continues to permeate today, from other expressions, the psychic and social fabric.

Keywords: liberation, Auschwitz, repercussions of the Shoah, subjectivity. 
Sostenemos que en el desencadenamiento del exterminio hay un punto de absoluta opacidad. Y que eso, como dice Primo Levi, es incurable. Algo del orden de lo irreparable lesionó el mundo humano, es decir, el discurso, la subjetividad. De la mano del novedoso exterminio inaugurado por el nazismo. Y esto no solo no puede quedar fuera de nuestra interrogación, sino que, de algún modo, es su guía. ¿Cómo inscribir lo irreparable?

Sneh y Cosaka (2000, p. 17)

El 27 de enero de 2020 se cumplieron 75 años de la «liberación» del campo de concentración y exterminio de Auschwitz-Birkenau. El 1 de noviembre de 2005, la Asamblea General de la Organización de las Naciones Unidas proclamó oficialmente esa fecha como el Día Internacional de Conmemoración en Memoria de las Víctimas del Holocausto, tomando como referencia ese evento de enero de 1945, en que las tropas soviéticas entraron en Auschwitz. Entre otras consideraciones, la onu afirmó que el Holocausto no es un tema solo judío, sino una preocupación universal, e instó a sus estados miembro a elaborar programas educativos para inculcar las enseñanzas del Holocausto con el fin de prevenir actos de genocidio en el futuro, con lo cual rechazaba toda negación parcial o total del Holocausto como hecho histórico (Organización de las Naciones Unidas, 2005).

A partir de algunos interrogantes surgidos en torno a esta temática, vigente por su interés y por su plus de metáfora, el presente trabajo reflexiona en relación a lo elicitado por la llamada «liberación» de los sobrevivientes de la Shoá, sus marcas en la subjetividad y sus repercusiones actuales, y problematiza su alcance desde distintas consideraciones. Ello incluye la propia implicación de pertenencia a la segunda generación, ubicada en la contemporaneidad cultural del siglo xx e inicios del siglo 
XXI, que produce resonancias afectivas que seguramente impregnan el texto, y las marcas que evidencian efectos de lo traumático en sus vertientes organizadoras y disruptivas de la organización psíquica, tanto en sus dimensiones psicoanalíticas como socioculturales.

Se hace necesario aclarar aquí que las tropas de los aliados, en la medida en que avanzaban hacia territorio alemán en sus ofensivas desde tres frentes diferentes, fueron «liberando» a los prisioneros de los campos que iban encontrando a su paso, desde noviembre de 1944 a mayo de 1945: los soviéticos a Majdanek, Plaszow, Auschwitz -Birkenau, Gross-Rosen, Sachsenhausen, Ravensbrück, Terezin y Stutthof, los norteamericanos a Natzweiler, Buchenwald, Flossenbürg, Dachau, Mauthausen y Ebensee, y los ingleses a Bergen-Belsen y Neuengamme.

Se encontraban a su paso con distintas situaciones disímiles. Solo a modo de ejemplo: campos vacíos sin ninguna huella de lo sucedido en Neuengamme, Alemania; la «liberación» o «rendición» de los alemanes y presos remanentes, en Dachau, Alemania; los 16 prisioneros abandonados en Natzweiler-Struthof, en Alsacia (en territorio francés y primer campo de Europa liberado, el 23 de noviembre de 1944); los 60.000 prisioneros de Bergen-Belsen, en Alemania (la mayoría gravemente enfermos por una epidemia de tifus, de los cuales 10.000 fallecieron en pocas semanas por esta o por desnutrición); o bien la multitud de prisioneros en Mauthausen, en Austria. La particularidad de Mauthausen era que los prisioneros españoles republicanos les dieron la bienvenida al ejército estadounidense con banderas republicanas, que sustituían a las nazis, con la puerta del campo cubierta por una gran pancarta con la leyenda: «Los españoles antifascistas saludan a las fuerzas libertadoras».

Los últimos campos «liberados» fueron Terezin (Theriesenstadt), en República Checa, el 5 de mayo de 1945 (donde la Cruz Roja Internacional asume al inicio el control), Ebensee el 6 de mayo, anexo a Mauthausen y Stutthof el 9 de mayo de 1945 (habiendo comenzado la evacuación en 
enero). Pero ya en 1943, tres de los seis campos de exterminio (Belzec, Sobibor y Treblinka), en Polonia, fueron desmantelados por los alemanes, quienes hicieron desaparecer toda evidencia de los crímenes cometidos, que ya «no existían» como tales.

Por lo tanto, desde este somero recorrido y en un primer nivel fáctico - para luego adentrarnos al nivel de la metáfora en un enfoque psicoanalítico-, surgen aquí algunos interrogantes: ¿los judíos fueron liberados en realidad por los aliados?, ¿se puede pensar en una fecha conmemorativa común, suficientemente representativa?, ¿por qué se elige para ello la fecha de la «liberación» de Auschwitz?

Si bien hay varias fechas de conmemoración (Levantamiento del Gueto de Varsovia, el Día de la Shoá, la Noche de los Cristales Rotos, fechas referentes a la desaparición o la «liberación» de los distintos lugares, entre otras), desde la evidencia histórica y las repercusiones en la subjetividad, se toma a Auschwitz como paradigma del exterminio sistemático, para el cometido de la Shoá, a través de fábricas de la muerte y de la maquinaria del horror, y del extremo al cual puede llegar la violencia humana.

Tomando en cuenta el punto de vista histórico y lo transmitido por los sobrevivientes y los «liberadores», el Dr. Mario Sinay (educador y pedagogo del Holocausto) analiza el concepto de liberación de los campos del nazismo. A su juicio, este es un concepto erróneo, en tanto plantea que en realidad los distintos tipos de campos (de concentración, de exterminio, de trabajos forzados...) ya habían sido evacuados en su mayoría: «Los sobrevivientes, que fueron abandonados y olvidados a su cruel destino durante toda la guerra, nunca se sintieron verdaderamente liberados y en todo caso se sintieron "liberados, pero no libres" (Sinay, 2020).

Para este autor, es necesario distinguir entre los términos liberación y evacuación de los campos nazis, un proceso complejo que se fue escalonando a lo largo de 1945, último año de la guerra. La mayoría de los campos habían sido abandonados por los alemanes y, en muchas situaciones, 
los prisioneros habían sido trasladados a otros campos, en Alemania, en las llamadas «marchas de la muerte», durante las cuales gran parte fallecía (asesinados, de agotamiento o de hambre). A los más débiles y enfermos se los abandonaba en los campos.

Algunos testimonios de sobrevivientes describen su sentir en ese momento. Abbaa Kovner (1988), poeta y partisano, segundo comandante en el Levantamiento del Gueto de Varsovia y uno de sus pocos sobrevivientes, escribe:

El día de la liberación fue recibido por los judíos con sentimientos confusos. Junto con la alegría y el regocijo, vino un profundo dolor que empañaba el brillo de tan ansiado día.

De todo rincón surgían las imágenes de la destrucción y los restos de la vida pasada que ya no volverían...

Y en el desfile de la victoria, los envolvió el luto y la desolación. (s. p.)

Jack Fuchs (2009) escritor y pedagogo sobreviviente de Auschwitz, se pregunta: «¿De qué liberación se habla?» y afirma que «el lenguaje nos juega una mala pasada. No hubo ninguna intención de terminar con los campos. La prioridad de los aliados nunca fue la de rescatar a las víctimas $[\ldots] »$ (s. p.).

Durante la guerra, los países aliados sabían muy bien de la existencia de los campos de exterminios y de todo lo que sucedía. Jamás bombardearon Auschwitz ni ningún campo. Ni las vías de tren que a ellos conducían. Auschwitz fue ignorado entre 1941 y 1945 . Voluntariamente ignorado. El objetivo de los países aliados era ganar la guerra. «Los sobrevivientes, los testigos que aún estamos vivos, fuimos encontrados, errando, en el camino autodestructivo de la humanidad» (Fuchs, 2009, s. p.).

En un artículo posterior, Fuchs (2012) continúa diciendo: 
En enero de 1945, los rusos ocuparon gran parte de Polonia y marcharon hacia Alemania. En el camino se "encontraron" con Auschwitz. Sí, es así. Se toparon con Auschwitz. Encontraron allí 7.000 enfermos, discapacitados, que no pudieron ser evacuados por los nazis, que, al ver que el ejército ruso se acercaba, intentaron sacar a todos los prisioneros que todavía podían caminar. La mayoría, enferma, desnutrida, no pudo seguir esa marcha, llamada la Marcha de la Muerte. Miles y miles murieron en el camino, no podían caminar y morían o directamente eran fusilados. (s. p.)

En referencia al primer texto de Fuchs, Daniel Goldman (2015) señala:

El reduccionismo al que nos somete la trama compuesta por la imagen y el lenguaje acaba desvirtuando de manera absoluta el insondable drama que contiene el propio horror. Porque en términos existenciales, ¿es posible liberarse de esa atrocidad? Y añado que hasta me parece injurioso recurrir al mismo término que los perpetradores usaron en el cartel de ingreso al campo de exterminio: "Arbeit macht frei”, "El trabajo libera”. Liberación versus liberación, ¿cuál de las dos tiene el derecho de portar la mayúscula? ¿Cuál de las dos emancipa a la otra? ¿Cuál de las dos no representa lo apócrifo? (s. p.)

Miriam Steiner, sobreviviente de Auschwitz y Ravensbruck, remite a un posible sentimiento de «esperanza fallida»:

Fue entonces cuando empezamos a comprender la gran pérdida...

Comenzamos a entender que seguramente ni la abuela ni el abuelo, ni la gran mayoría de la familia, volvieron.

Solamente ese primo y también su padre volvieron después.

Dijeron que nosotros no podíamos esperarlo, pero la verdad es que 
nosotros esperábamos todo el tiempo a papá.

Y yo sólo quiero contar que más de una vez yo miro como buscando... no a papá, es a mi hermano al que hasta ahora busco todo el tiempo, y ya sé que no es realista en modo alguno, y no es exactamente que busco, yo exploro con los ojos [...]. (Kleiman y Springuer, 1995, p. 38)

Miriam Akavia (s. f.), sobreviviente del campo de Plashov y de Auschwitz, describe el momento de «la liberación» de esta manera:

Creí que debía estar contenta, sentí las lágrimas, pero sabía que tenía que alegrarme. Comencé a llorar, pensé: ¿Qué es lo que me quedó? Y el primer pensamiento que pasó por mi mente fue: qué lástima que llegaron demasiado tarde. Todo el mundo está destruido, todo lo digno en el mundo había desaparecido. (s. p.)

Reflexionar sobre la Shoá en la actualidad supone el abordaje de un acontecimiento complejo y polifacético, un «fenómeno no resuelto» (Cyjon, 2018), devastador para la humanidad, que se ha inscrito de forma indeleble a nivel psíquico y social y que, entre otros aspectos, evidencia repercusiones en la subjetividad de los sobrevivientes y sus descendientes, en su lugar de testigos-escuchas vivientes. Este acontecimiento, frontera entre lo psíquico y lo social, posee una dimensión de fenómeno de la humanidad que no admite conceptualizaciones simples y lineales. La relevancia otorgada a la memoria a través de los testimonios de los sobrevivientes y estos testigos-escuchas permite generar espacios analíticos para el intento de su comprensión, con las limitaciones de su complejidad, en lo que son más los interrogantes abiertos que las respuestas.

Es así que, ya posicionados desde un enfoque psicoanalítico, la evidencia de los testimonios anteriores - y de otros que no es posible mencionar aquí- señala que el primer momento no puede ser caracterizado 
ni vivido como liberación, en tanto se marca una contradicción o ambivalencia entre la alegría por la liberación y el dolor inmenso que esta provocó. Esta vivencia acompañó a los sobrevivientes a lo largo de su vida, entrampados en un tiempo congelado en un pasado que, por muchas décadas, les resultó difícilmente compartible con las generaciones siguientes y la sociedad.

Salvo las contadas excepciones de sobrevivientes que sostuvieron la brújula del testimonio-escritura para denunciar lo ocurrido, para mantener viva la memoria y como forma de poder seguir viviendo (entre otros, Primo Levi, Eli Wiesel, Jorge Semprún, Robert Antelme, Paul Celan y Ana Vinocur en nuestro país), reinaba en general un pacto de silencio, instalado especialmente con la segunda generación y la sociedad. No era callado, ya que lo no dicho se expresaba fuertemente en gestos y actitudes que lo denunciaban y que fueron interpelados a través de las generaciones, fundamentalmente a partir de la tercera. Sin embargo, estas vivencias de soledad y desolación por el horror vivido por los padres — que afectó la subjetividad de la segunda y tercera generación, ambas receptoras y transmisoras - fueron alternando con la imperiosa necesidad de regresar a la vida, de reconstruirla en nuevos espacios geográficos y psíquicos, a saber: el baby-boom inmediato a la «liberación», los distintos proyectos vitales y variadas creaciones, frutos de una resiliencia sorprendente.

Retomando la línea de las dificultades de experimentar el sentimiento de liberación, con una presentificación del pasado, el sobreviviente y sus descendientes experimentan un tiempo congelado, con el miedo consiguiente al encierro y, por lo tanto, a no poder salir y con la certeza de no haber salido nunca. La sensación de pérdida aparece con todo su vigor y algo queda irremediablemente perdido. El doliente permanece inserto en una situación incierta e indefinida, abocado a rehacer su vida, pero al mismo tiempo quedando aferrado al objeto perdido con la misión — relacionado con sus intensos sentimientos de culpa por haber sobrevivido- de 
devolverlo a la vida. Resignar el objeto y olvidarlo serían vivenciados como una traición al ser querido. Las imágenes indelebles ligadas a escenas de tortura, sufrimiento y desamparo de víctimas y formas de muerte inenarrables tampoco lo permiten. Y esto se transmite también a los hijos.

En un trabajo anterior decíamos que la Shoá

provocó un viraje radical de lo familiar y previsible (Das hemlich) a lo extraño, inquietante, siniestro (Das unheimlich), introduciendo profundas transformaciones a nivel psíquico y en el entorno social y cultural, perfilándose así un "contexto social siniestro" — concepto acuñado por Lutenberg (2002) — que las nuevas generaciones hemos tratado de abordar y tramitar. (Zytner Tessler, 2013, p. 46)

Más de ochenta años después, más allá de su propia especificidad, sigue constituyendo un baluarte paradigmático y emblemático de lo que han sido y siguen siendo episodios extremos de catástrofe social que dan cuenta, radicalmente, de la violencia extrema ejercida por un ser humano sobre otro y que siguen impregnando actualmente, desde otras expresiones, el entramado psíquico y social, plasmados en marcas de vulnerabilidad. Rodríguez Rendo (2012) lo denomina «estar a la intemperie», al desamparo en la época actual, que impacta al psiquismo; el sujeto debe convivir con el miedo que, por lo tanto, lo deja a la intemperie. Este miedo es inseparable del escenario de la modernidad líquida a la que alude Zygmunt Bauman (2008) y, asimismo, al de los efectos de la Shoá en los involucrados.

En su texto Inhibición, sintoma y angustia, Freud (1976) distingue la angustia (sin objeto) del miedo (con objeto), que es la que emerge cuando el desamparo se reactiva en la vida adulta. El sujeto se queda a la intemperie, habiéndose producido una maniobra en la que concurren el peligro externo y el interno, de lo que se constituye el nexo con la situación traumática: exigencia pulsional y amenaza exterior. El estado de desamparo 
se considera el prototipo de la situación traumática. En el curso de su vida, el impacto de un acontecimiento que haga eco en su marca traumática va a producir la reactivación del desamparo. En cada oportunidad que algo abrupto irrumpa desde fuera o desde dentro, ese acontecimiento traumático se conectará con el desamparo. En este escenario sostenido a través del tiempo, ¿cómo se podría hablar de liberación?

Un enfoque interesante es el planteado por Fethi Benslama (2006) en un artículo sobre la representación y lo imposible, en el que señala:

El genocida deja, mediante su acto, misivas genealógicas psíquicamente destructivas de la representancia, que van a operar sobre varias generaciones, con tantos más estragos en la medida en que ha habido negación, silencio o borramiento de la destrucción y de sus responsables. Lo irrepresentable transporta entonces el accionar de la crueldad más allá de su acción. (p. 259)

El nazismo, según Daniel Gil (1996), intentó «destruir el orden humano, su memoria, la muerte misma, como estructura simbólica que permite la memoria» (s. p.), lo que acarreó una pérdida de memoria de la humanidad.

Otro aspecto interesante a considerar para la comprensión de ese pasado presentificado en la memoria es el que brinda el historiador Henry Rousso (1988), quien sugiere que estamos inmersos en el «tiempo de la memoria», «en una relación afectiva, sensible, incluso dolorosa, con el pasado», donde «en la hora actual, el pasado reciente se nos presenta con una intensidad sin igual», que «reviste una actualidad inédita, como consecuencia de la dificultad de asumir las tragedias del siglo xx» (p. 338). Y ello nos vincula nuevamente a la necesidad de la reflexión para el intento de comprensión y elaboración de ese pasado presentificado. 
Ya Freud (1986) planteaba que «ninguna generación es capaz de ocultar a la que sigue sus procesos anímicos de mayor sustantividad». En este sentido, Maren Ulriksen de Viñar (1997) señala que la reflexión «surge de los efectos a posteriori de la generación siguiente» y que «opera como un esfuerzo para atravesar el espesor del desconocimiento, levantar la desmentida, restituir el trabajo de la memoria y hacer reconocer el carácter y la extensión del terror» (s. p.). En este proceso cambian las reglas de juego, ya que «se trata de una empresa de renacimiento, de restitución de engramas destruidos, que continúa a lo largo de las generaciones [...] y que intenta abordar el silencio compartido» (s. p.).

Se constituye también en una forma de abordar un «duelo de características especiales» (Kijak y Pelento, 1985), «un duelo suspendido» a la espera de que las generaciones posteriores puedan asumirlo y convivir con él, en lugar de «elaborarlo» (Bodnar y Zytner Tessler, 2003), o bien se aproximen a una posible «liberación», donde la transmisión y reflexión colaborarían en la metabolización del terror en dolor, especialmente a través de un tercero (otro social) que intente habilitar la posibilidad del proceso de duelo (Viñar y Ulriksen de Viñar, 2000).

El concepto de «identificación radiactiva», de Yolanda Gampel (1993), constituye otro aporte para comprender el intento de elaboración de este duelo, así como para borrar el dolor y los efectos en sus hijos. Esta actúa como los efectos de la radiación, en tanto impide que el psiquismo pueda protegerse de su penetración, implantación y efectos. Serían penetraciones de aspectos terribles y destructivos de la realidad externa, no representables, actuadas en ocasiones por los sobrevivientes o sus hijos, que impregnan el tejido social, como caja de resonancia. A su vez, los hijos experimentan una transposición de otra realidad de potencialidad traumática experienciada por sus padres (Kestenberg y Robbin, 1975), que involucra además la construcción de su subjetividad. 
Con el intento de afrontar el pensar lo impensable desde las generaciones actuales, se posibilitaría el desafío de franquear la inapelable respuesta del ss mencionado por Primo Levi (1988). Frente a la atónita pregunta del prisionero: «Warum?» (‘¿Por qué?’), por la crueldad sin motivo, el ss responde: «Hier ist Kein Warum» ('Aquí no hay ningún por qué’). Si el terror se opone al pensar, es de orden ético, además, revertir esa imposibilidad, aún con la permanencia de la «oscura opacidad» (Sneh y Cosaka, 2000) que nos siguen planteando las zonas grises de la Shoá.

Asimismo, la permanencia de esa oscura opacidad se puede relacionar con las vivencias en torno a la «liberación» de los sobrevivientes de la Shoá y sus marcas en la subjetividad, que señalan la intensidad del sentimiento de culpa de los sobrevivientes por haber sobrevivido y el silencio consecuente. Las fuentes de culpa se multiplican: la incapacidad de salvar a sus seres queridos, las condiciones generadas por el cambio de código referencial en la cotidianeidad y la arbitrariedad absoluta de las normas (por ejemplo, en los guetos y campos de concentración), las experiencias extremas vividas, la ruptura con los parámetros conocidos de convivencia, los dilemas imposibles de resolver..., y la lista es infinita...

«¿Por qué yo me salvé?», se preguntan una y otra vez con desconsuelo los sobrevivientes. En numerosos testimonios se escuchan sus voces transmitiendo que con el silencio querían proteger a sus hijos, querían olvidar y reconstruir su vida; sentían que no los podían comprender, experimentaban intensa culpa de haber sobrevivido, se avergonzaban de situaciones vividas en la guerra, entre otras muchas expresiones. Y ello se vincula con el impacto del silencio en la segunda generación, los hijos de los sobrevivientes.

Nadine Fresco (1984) lo investiga a través de sus testimonios y describe el vertiginoso agujero negro de una memoria de muerte prohibida, que se manifestaba, en ocasiones, en incomprensibles ataques de pena. Los padres no explicaban nada; los hijos no preguntaban nada, cubiertos 
de un manto de implacable silencio, incapaces de transgredir la prohibición; letanías de silencio, que subrayan un objeto invisible enclaustrado en una evocación imposible... Fresco (1984) encuentra en ellos el sentimiento de irreparable nostalgia de un mundo del que sienten que fueron excluidos al nacer, y el vértigo de la confrontación con el pasado, objeto perdido de un deseo innombrable, donde el sufrimiento toma el lugar de algo heredado. Para ellos, su existencia es como una especie de exilio, no de un lugar en el presente o en el futuro, sino de un tiempo que se ha ido para siempre y los ha dejado con una identidad trunca, como una cadena de sustituciones, donde la presencia de un sentimiento de culpa dificulta la oposición, la ambivalencia y la hostilidad necesaria para el crecimiento.

Estas marcas en la subjetividad que describimos tanto en los sobrevivientes como en sus descendientes podrían aludir a lo que, en un trabajo en coautoría con Luba Bondnar (2000), denominamos como «huella de vulnerabilidad» que se transmite de generación en generación:

Parecería como si en el sufriente quedara un "surco" que luego cada cual llenará con experiencias propias-ajenas, muchas veces traducidas en identificaciones alienantes con el sobreviviente. En palabras de una hija de una sobreviviente: "Todo esto es parte de mi identidad... Soy maestra, soy mamá, soy casada, soy hija de sobreviviente... No puede existir que eso no esté... ¡Está enrabado en mí, está siempre siempre, siempre está ahí! [...] Yo pensaba que la Shoá, el nazismo, me había llegado cerca y después me di cuenta que no me llegó cerca... ¡me agarró, me tocó y me tiene! ¡Y está allí! Este tema siempre está entrelazado en mi vida, está en mi vida, es parte permanente de mi vida". (Bodnar y Zytner Tessler, 2003, s. p.) 
La metáfora de la vela conmemorativa, introducida por Dina Wardi (1992), aporta también a esta temática. Constituye la designación inconsciente que hacen los padres sobre la misión del hijo de recordar a los familiares muertos en la Shoá, como forma de llenar el vacío dejado por su ausencia y de mitigar el dolor de un duelo imposible de elaborar. Deben servir como eslabón que preserve el pasado y lo una al presente y el futuro, que mantenga viva su memoria. Esta constituye una pesada carga que compromete la propia identidad en pro de dar consuelo a sus progenitores, en ocasiones a costa de la posibilidad de discriminación e individuación. Implica el fracaso de un proceso simbólico, por lo cual las velas conmemorativas se convierten en memoriales-vivos para los muertos y se transforman en un aspecto inseparable del ritual de duelo que no pudo llevarse a cabo por los padres.

Actualmente, son la tercera y la cuarta generaciones las que interpelan e invitan a romper un silencio compartido con la generación anterior, la de los hijos, una generación bisagra en muchos sentidos. Y a través de este reclamo, la segunda se siente más habilitada, finalmente, a preguntar... y a poder escuchar... Son los nietos los que se atreven a preguntar lo que los hijos no pudieron. Algunas de sus expresiones son: «Hay que seguir la cadena, continuar con la antorcha, para que no se pierda», «La gente tiene que conocer lo que pasó», «Los sobrevivientes ya se están yendo...», "Para luchar contra el negacionismo».

Es así que, por intermedio de distintos caminos, a través de la formación en la temática, del arte, del intercambio con sus familiares y grupo de pares, de instancias psicoterapéuticas y otros espacios, los descendientes de los sobrevivientes de la Shoá se brindan la posibilidad de explorar en torno a la llamada «liberación» de los campos de concentración y las marcas de ello en la subjetividad. Pueden lograr, entonces, en un proceso compartido con otros descendientes, renovar la cadena generacional para evitar quedar atrapados en el círculo sin salida del pasado y para 
encontrarse con aspectos más realistas de la historia de sus familiares sobrevivientes, encarnando retazos informes transmitidos..., fragmentaciones de la memoria (Viñar y Ulriksen de Viñar, 1996).

Las creaciones artísticas muchas veces habilitan una puesta en escena y cumplen con la función de organizadores inconscientes que van desde la vivencia y la reflexión, hasta una puesta en sentido, que ubica tanto la significación singular que para el deudo posee la muerte de sus familiares, como la significación social en un cruce de la historia individual y la historia social.

Para finalizar, rescatamos la idea de la inexorable pertenencia a la especie humana, defendida a ultranza por Robert Antelme (1996), que privilegia un intento de comprensión crítica en esta temática que trasciende una repetición meramente catártica y que jaquea la hipótesis de Giorgio Agamben (2000), que afirma que en situaciones concentracionarias extremas (campos de exterminio) el judío se transformaba en no-hombre. Nos ilumina también el entendimiento de la misma sobrevivencia humana..., de la intensa, incansable y permanente lucha de los sobrevivientes por mantenerse íntegros en su humanidad.

\section{REFERENCIAS BIBLIOGRÁFICAS}

Akavia, M. (s. f.) Archivo de Yad Vashem, O.3, V.T/4543 [material inédito]. Agamben, G. (2000). Lo que queda de Auschwitz. El archivo y el testigo. Homo Sacer III. Pre-textos.

Antelme, R. (1996). La especie humana. Trilce.

Bauman, Z. (2008). Miedo líquido. Paidós. 
Benslama, F. (2006). La representación y lo imposible. El psicoanálisis en tiempos de terror. Revista de la Asociación de Psicoanálisis de Buenos Aires. 28(2), 247-273.

Bodnar, L. y Zytner Tessler, R. (2003). Yo canto una canción que se llama silencio. En R. Kristal de Burstein, M. Sornaiuolo y M. C. Raffo (eds.), Desplegando alas, abriendo caminos. Sobre las huellas de la violencia (pp. 233-246). Centro de Atención Psicosocial.

Cyjon, R. (2018). La Shoá, un fenómeno no resuelto. Nacionalsocialismo, Shoá, historia y memoria: reflexiones de intelectuales y debates historiográficos. Departamento de Estudios Judaicos de Universidad ORT.

FRESCO, N. (1984). Remembering the Unknown. Internacional Review of Psychoanalysis (s. d.).

FREUd, S. (1976). Inhibición, síntoma y angustia (1926 [1925]). En Obras completas (vol. xx, pp. 71-164). Amorrortu.

FREUD, S. (1986). Tótem y tabú. Algunas concordancias en la vida anímica de los salvajes y de los neuróticos (1913 [1912-13]). En Obras completas (vol. xIII, pp. 1-164). Amorrortu.

Fuchs, J. (2009, 27 de enero). La liberación de Auschwitz o las trampas del lenguaje. Página12. https://www.pagina12.com.ar/diario/contratapa/13-118957-2009-01-27.html

Fuchs, J. (2012, 24 de enero). ¿Liberación? Página 12. https://www.pagina12.com.ar/diario/contratapa/13-186073-2012-01-24.html

GAmpel, Y. (1993). Prendre congé: Despedirse del propio pasado a través de la mente del analista. Revista de Psicoanálisis con niños y adolescentes, 6, 23-35.

GiL, D. (1996). Memoria de la muerte [artículo inédito]. Asociación Uruguaya de Psicoterapia Psicoanalítica.

Goldman, D. (2015, 15 de enero). Liberación versus liberación. Página 12. https://www.pagina12.com.ar/diario/contratapa/13-263928-201501-15.html 
Kestenberg, J. S. y Robbin, E. (1975). Children and Parents: Psychoanalytic Studies in Development. J. Aronson.

KiJAK, M. y Pelento, M. (1985). El duelo, en determinadas situaciones de catástrofe social. Revista de la Asociación Psicoanalitica Argentina, $42(4)$.

Kovner, A. (1988). MiSheló VeAlav [material inédito]. Moreshet Sifriat Poalim, Tel Aviv.

LeVI, P. (1988). Si esto es un hombre. Milá.

Organización de LAS Naciones Unidas (2005). El Holocausto y el Programa de divulgación de las Naciones Unidas. Informe del Secretario General. shorturl.at/nrsA0

Rodríguez Rendo, M. C. (2012). El sujeto a la intemperie. La cuestión del desamparo en Freud y en Lorca. Norte de salud mental, X(42), 37-47. https://ome-aen.org/biblioteca/revista-norte/

Rousso, H. (1998). La hantise du passé: entretien avec Philippe Petit. Textuel. Sinay, M. (17 de mayo, 2020). Abandonados y olvidados a su suerte [videoconferencia]. Centro Recordatorio del Holocausto, Uruguay.

Sneh, P. y Cosara, J. C. (2000). La Shoah en el siglo: del lenguaje del exterminio al exterminio del discurso. Xavier Bóveda.

Kleiman, I y Springer, N. (1995). El dolor de la liberación. Yad Vashem.

UlRIKSEN DE ViñaR, M. (1997). Notas para pensar el terror de estado y sus efectos en la subjetividad. Revista Uruguaya de Psicoanálisis, 86. www.apuruguay.org/apurevista/1990/1688724719978614.pdf

Vezzetti, H. (1988, noviembre). Responsabilidades de la memoria [ponencia]. Coloquio Memoria social, comunidades y fragmentaciones, Montevideo.

Viñar, M. y UlRiKSEn de Viñar, M. (1996). Fracturas de la memoria. Crónicas de una memoria por venir. Trilce.

ViñaR, M. y UlRIKSEN DE ViñaR, M. (2000, marzo). Los crímenes del siglo XX. Historia, verdad y justicia [ponencia]. Universidad de Siena. 
WARDI, D. (1992). Memorial Candles: children of the Holocaust.

Tavistock/Routle.

Zytner Tessler, R. (2013, julio). Semblanzas de lo siniestro: en torno a algunas repercusiones de la Shoá en la actualidad. Revista Psicoanálisis e intersubjetividad, 7. www.intersubjetividad.com.ar/semblanzas-delo-siniestro-en-torno-a-algunas-repercusiones-de-la-shoa-en-la-actualidad/

Zytner Tessler, R. (2018). Marcas del desamparo: sobre algunas repercusiones de la Shoah en la actualidad... Revista Uruguaya de Psicoanálisis, 12(127), 46-57. www.apuruguay.org/apurevista/2010/ 16887247201812705.pdf 
